American Journal of Pharmaceutical Education 2019; 83 (5) Article 6759.

\title{
RESEARCH
}

\section{Value of Pharmacy Students Performing Population Management Activity Interventions as an Advanced Pharmacy Practice Experience}

\author{
Elizabeth C. Cannon, PharmD, ${ }^{a}$ Emily B. Zadvorny, PharmD, ${ }^{\mathrm{b}}$ Sarah D. Sutton, PharmD, ${ }^{\mathrm{a}, \mathrm{b}}$ \\ Sheila L. Stadler, PharmD, ${ }^{\mathrm{a}, \mathrm{b}}$ Leslie K. Ruppe, PharmD, ${ }^{\mathrm{a}, \mathrm{b}}$ Deanna Kurz, BA, ${ }^{\mathrm{a}}$ Kari L. Olson, PharmD ${ }^{\mathrm{a}, \mathrm{b}}$ \\ ${ }^{a}$ Kaiser Permanente Colorado, Aurora, Colorado \\ ${ }^{\mathrm{b}}$ University of Colorado Skaggs School of Pharmacy and Pharmaceutical Sciences, Aurora, Colorado \\ Submitted August 28, 2017; accepted June 6, 2018; published June 2019.
}

Objective. To assess the value of an advanced pharmacy practice experience in which students engaged in population health management (PHM) activities for a managed care setting.

Methods. Students were provided with a list of patients, trained on the requirements for each PHM activity and completed them independently. The students reviewed the electronic record for each patient on their list to identify those who were non-adherent to dual antiplatelet therapy (DAPT) within one year of coronary stent placement, non-adherent to beta blockers (BB) within six months post-acute myocardial infarction, or with renal dysfunction and requiring dose adjustment of lipid-lowering therapy. Students coded each intervention based on predefined categories such as patient education, medication discontinuation, or medication reconciliation, and then if necessary were reviewed with the pharmacy preceptor. The primary investigator determined the intervention to be either actionable or non-actionable. The primary outcome was the proportion and type of interventions made by each student. The secondary outcome was clinical pharmacist time offset. A retrospective, data-only pilot study was conducted to determine the outcomes from the program over four years.

Results. Forty-six students made 3,774 interventions over the study period, 37\% of which were categorized as actionable. The most common actionable interventions were providing patient education $(52 \%)$, verifying prescription adherence $(23 \%)$, and medication therapy adjustment $(10.5 \%)$. Over the study period, an estimated 765.6 hours of clinical pharmacist time was offset, or approximately 191.4 hours per academic year.

Conclusion. This study demonstrated that a population health management approach can be used successfully within an APPE. This approach can result in offset pharmacist time for precepting organizations, while offering meaningful clinical interventions for patients and learning opportunities for students.

Keywords: pharmacy students, clinical interventions, advanced pharmacy practice experience, population management

\section{INTRODUCTION}

Accreditation Council for Pharmacy Education (ACPE) Standards for the Doctor of Pharmacy (PharmD) curriculum mandate that pharmacy students complete advanced pharmacy practice experiences (APPEs) in the following settings: community pharmacy, hospital or health-system pharmacy, ambulatory care, and inpatient/acute care general medicine. ${ }^{1}$ ACPE standards and guidelines also recommend that APPEs include direct interaction with populations and individual patients and

Corresponding Author: Elizabeth C. Cannon, Kaiser Permanente Colorado, 2045 Franklin St., Denver, CO 80205. Tel: 303-317-7519. Fax: 303-764-4380. E-mail:

elizabeth.c.cannon@kp.org. collaboration with providers as these activities foster an increased level of independence and rigor in students. These APPE recommendations are intended to ensure that future pharmacists have the ability to provide patientcentered and population-based care that optimizes medication therapy. ${ }^{1}$

Given the experiential education requirements of the PharmD program, practicing pharmacists are needed to support the professional and clinical development of pharmacy students. It has long been the mission of many pharmacy departments and a commitment of many preceptors to teach pharmacy students in the APPE setting. However, as practicing pharmacists become busier and their voluntary precepting time becomes increasingly limited, the effectiveness, efficiency, and overall value 


\section{American Journal of Pharmaceutical Education 2019; 83 (5) Article 6759.}

of the APPE program to their business or practice must be considered. $^{2,3}$

The value of APPEs has been evaluated across a variety of practice settings including ambulatory care, community practice, and advanced institutional and adult medicine. Several studies that assessed the benefits of having pharmacy students work in the ambulatory care setting have been published. ${ }^{4-9}$ Some of these studies quantified both the clinical and economic impact of APPE students' therapeutic interventions by assessing the number and types of interventions they performed, thus providing an estimate on cost avoidance and/or savings. ${ }^{4-9}$

The Clinical Pharmacy Cardiac Risk Service (CPCRS) at Kaiser Permanente Colorado (KPCO) has a long-standing relationship with several schools of pharmacy and participates in introductory and advanced pharmacy practice experience programs. In 2011, the CPCRS devised an APPE learning experience that aligned with ACPE goals and would give students increased "ownership" of and independence in performing specific population health management (PHM) activities that were both patient-centered and population-based. Working from aggregated patient data gathered from health information technology resources, students reviewed patient records and identified interventions either they or a clinical pharmacist could make to improve both clinical and financial outcomes in targeted areas via three PHM activities. Through the PHM activities, the students targeted interventions that they could make or that a pharmacist could make during routine follow-up patient care, thereby saving the pharmacist time. To the authors' knowledge, there has not been a published report that evaluated the value of student led PHM activities. The objective of this study was to assess the value of an APPE in which pharmacy students conducted PHM activities in a managed-care setting by describing the number and type of interventions performed by students and potential pharmacist offset time.

\section{METHODS}

The Clinical Pharmacy Cardiac Risk Service is a team of clinical pharmacists at KPCO that manage patients with established atherosclerotic cardiovascular disease (ASCVD) within a telemedicine model. The service uses a population-based approach to long-term medication management for approximately 16,000 enrolled patients. The CPCRS's clinical pharmacists ensure that appropriate cholesterol-lowering, hypertension, and diabetes medications are initiated and adjusted in patients with ASCVD. Patients are also evaluated to ensure that additional medications shown to reduce the risk of future cardiac events, such as aspirin, beta-blockers, and ACEinhibitors, are initiated when appropriate. The CPCRS team works with primary care providers, cardiologists, endocrinologists, and neurologists under collaborative drug therapy management (CDTM) protocols to optimize outcomes of patients with ASCVD. All patients are offered evidence-based therapies and their health is managed according to CDTM protocols.

At KPCO, electronic medical records (EMRs) are used to document the care of all patients. The majority of patients use internal pharmacy and laboratory services. Therefore, each patient's laboratory results and medication fill history are automatically uploaded into the patient's EMR. ${ }^{10}$

Based on quality service and safety considerations for the ASCVD population they served, preceptors with the CPCRS identified three PHM activities that fourthyear PharmD students could conduct with minimal supervision. The PHM activities involved reviewing EMRs to identify patients who were non-adherent to dual antiplatelet therapy (DAPT) within one year of coronary stent placement, were non-adherent to beta-blockers (BBs) within six months after acute myocardial infarction, or had renal dysfunction and potentially required dose adjustments of lipid-lowering therapy. These areas were chosen for intervention based on pharmacists' belief that these cases were high priority for clinical safety and efficacy reasons, and important to maintaining high-quality measures for KPCO.

Lists for each of the three PHM activities were generated for each new group of APPE students (approximately every six weeks) throughout the year. The PHM activities were equally divided among the pharmacy students on rotation at KPCO. The students were trained by a clinical pharmacist at the beginning of each APPE using a structured workflow devised by the CPCRS. This detailed workflow ensured consistency in care delivery, documentation, and students' ability to work largely autonomously. Students reviewed each EMR to verify that the patient met eligibility criteria to be included in the PHM activity and consulted with a clinical pharmacist as needed. For example, if it appeared that a patient had not refilled his prescription for beta-blockers in a timely manner as determined by the student reviewing the patient's prescription refill history, this would potentially warrant an outreach. When indicated, students worked with a clinical pharmacist to create a patient care plan and notified the patient's physicians by placing a message in the EMR. When an intervention was warranted, the student was responsible for contacting the patient and documenting the action taken in the patient's EMR. If a patient requested information in writing or if the student 


\section{American Journal of Pharmaceutical Education 2019; 83 (5) Article 6759.}

was unable to reach the patient by phone, the student and clinical pharmacist would discuss the situation and decide whether a letter should be mailed to the patient. In addition to EMR documentation, students noted the intervention they made and the amount of time they spent in Excel. Estimates of time invested were documented for both indirect (ie, the time spent assessing the patient's status via the EMR) and direct (ie, contact with the patient and/or other health care providers) interventions. All students dedicated approximately $50 \%$ to $60 \%$ of their APPE hours to the PHM activities

Interventions completed by students during this timeframe were catalogued into clinical intervention categories (Table 1). Clinical intervention categories were classified further as actionable or non-actionable. Chart reviews of cases where no further action was warranted at that time were classified as non-actionable. Interventions performed included: new medication started, medication discontinued, medication reconciliation, medication therapy adjustment, restart medication, patient education, verification, and other. Other data that students collected included: medical record number (MRN), date the PHM activity list was generated (month/year), PHM activity type (ie, non-adherent to BBs, non-adherent to DAPT, or renal dysfunction), clinical intervention categories, and time (direct and indirect) spent on patient care. To account for non-independent student work, in March 2015 clinical pharmacists were retrospectively surveyed regarding the average number of minutes they spent per PHM activity to review, discuss, and document their work with a student.

The primary study outcome was the proportion and type of interventions performed by students (eg, number of $\mathrm{BB}$ interventions divided by the total number of interventions, then multiplied by100). The secondary outcome measures included average time spent by students and clinical pharmacists on each PHM activity and the potential offset of clinical pharmacist time as a result of the students' work.
Descriptive statistics were used to evaluate both the primary and secondary outcomes. Means, medians, and standard deviations were used for interval- and ratio- level variables and proportions for nominal- and ordinal-level data.

This was a pilot study evaluating PHM activities using retrospective data only that was completed between May 1, 2011 and March 31, 2015. This study was reviewed by the Kaiser Permanente Colorado Institutional Review Board (IRB) and deemed IRB exempt.

\section{RESULTS}

During the study period (May 2011 through March 2015), 3,774 interventions were performed by 46 students. On average, two APPE students were on rotation at the CPCRS for each of 28 rotation cycles. During the study period, 17 different preceptors were involved in the program. Of the 3,774 interventions, the proportion per PHM activity was: 41\%, BB $(n=1,540) ; 40 \%$, DAPT $(\mathrm{n}=1,519)$; and $19 \%$, renal dysfunction $(\mathrm{n}=715)$ (Figure 1). Sixty-three percent $(n=2,368)$ of all interventions were categorized as non-actionable; the remaining 37\% $(n=1,406)$ were actionable (Figure 1$)$. The actionable interventions included all clinical intervention categories except chart review. The most common actionable interventions were patient education $(n=731,52 \%)$, verification $(\mathrm{n}=328,23 \%)$, and medication therapy adjustment $(\mathrm{n}=148,10.5 \%)$ (Figure 2).

The proportion of each clinical intervention category based on PHM activity is depicted in Table 2. The most common clinical intervention category for patients with renal dysfunction was medication therapy adjustment (73.9\%). The most common clinical intervention category for patient non-adherence to a BB or DAPT was patient education (46\%). Of note, for BB non-adherence, the second most common clinical intervention category was verification (38\%).

The estimated average clinical pharmacist time offset for actionable interventions were 13.1 minutes per

Table 1. Description of each Clinical Intervention Category

New Medication Start, de novo medication starts

Medication Discontinuation, recommendation to stop a medication.

Medication Reconciliation, any medication administration clarification.

Medication Therapy Adjustment, any dose or medication change within the same medication class.

Restart Medication, any time a medication was restarted after a period of discontinuation for any reason.

Patient Education, student directly contacted a patient (via phone or letter) for sole purpose of education.

Verification, student calls a non-Kaiser Permanente pharmacy to verify patient refill history.

Chart Review, patient cases where no student action was required, no patient contact was made, and therefore no clinical intervention was made.

Other, any action taken by student that does not fall into other categories 


\section{American Journal of Pharmaceutical Education 2019; 83 (5) Article 6759.}

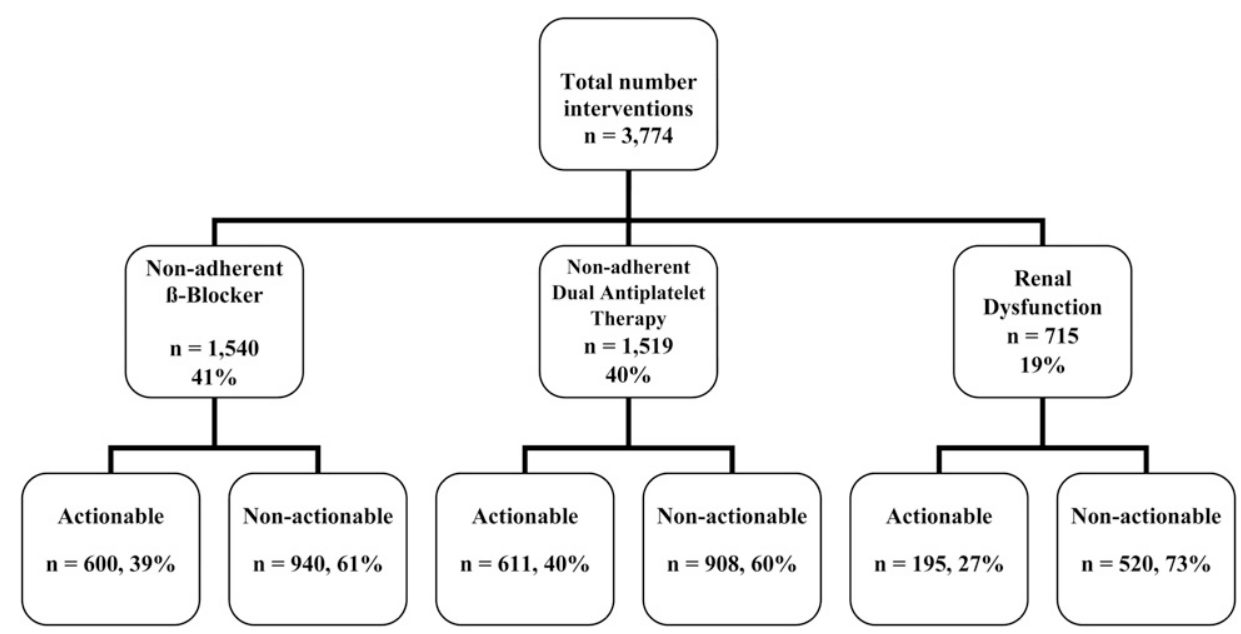

Figure 1. Number and Proportion of Actionable and Non-Actionable Interventions per Population Health Management Activity (PHMA)

intervention for cases of BB non-adherence, 11.7 minutes for cases of renal dysfunction, and 16.8 minutes for cases of DAPT non-adherence (Table 3). Over the study period, an estimated 340.1 hours of clinical pharmacist time was offset by actionable interventions identified by and completed by or with the help of pharmacy students (Table 4). Non-actionable chart reviews by pharmacy students offset 425.5 hours of clinical pharmacist time as pharmacists did not have to review those charts. Combined, the non-actionable and actionable interventions resulted in a total of 765.6 hours (approximately 191.4 hours per academic year) of clinical pharmacist time offset over the study period.

\section{DISCUSSION}

In addition to fulfilling their own patient care responsibilities, APPE preceptors remain committed to training students according to the standards set forth by ACPE. We describe a process for maximizing the efficiency and benefits of integrating pharmacy students into important patient care activities using a largely independent work model. Implementation of PHM activities in this APPE setting provided students a unique way to conduct a large number of interventions and make a significant impact in terms of patient care and organizational time saved. Anecdotally, clinical pharmacists and students have reported the value of and their satisfaction with the PHM model described here. In this model, patients are receiving services that would not exist to the same extent within the normal CPCRS workflow. Although many of these interventions may have been completed at a regularly scheduled follow-up appointment with the patient's clinical pharmacist (often months later), by proactively

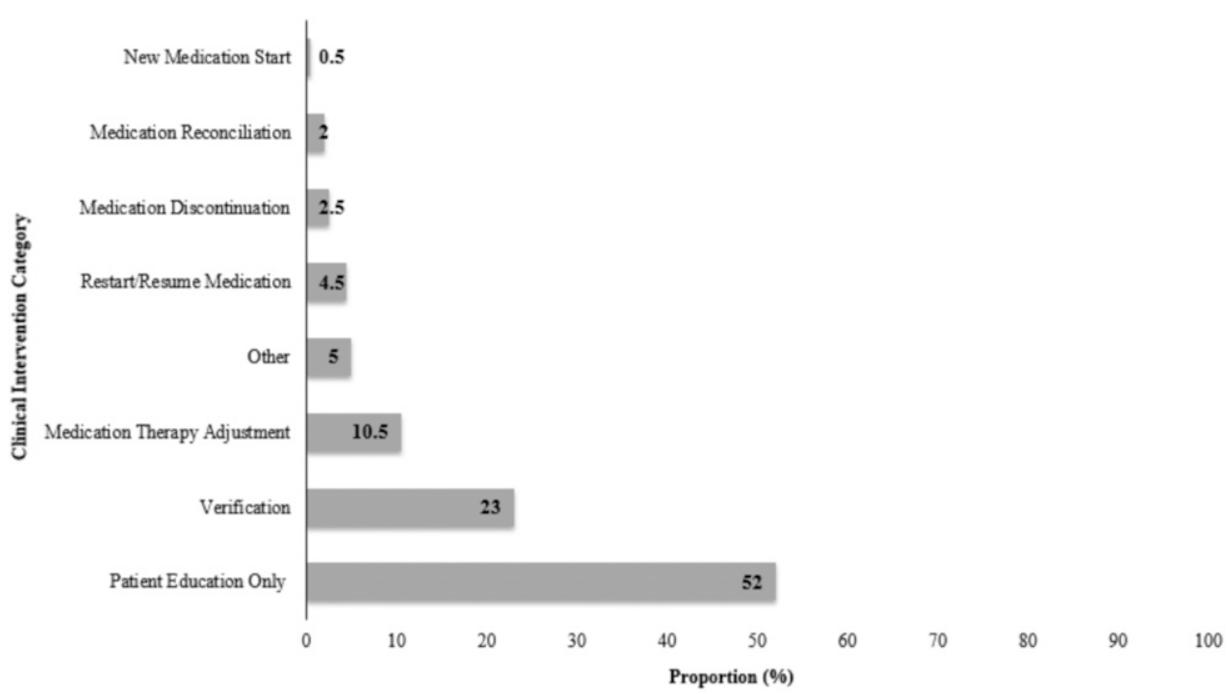

Figure 2. Actionable Interventions: Proportion (\%) per Clinical Intervention Category 


\section{American Journal of Pharmaceutical Education 2019; 83 (5) Article 6759.}

Table 2. Number and Percentage of Each Clinical Intervention Category per Population Health Management (PHM) Activity

\begin{tabular}{|c|c|c|c|}
\hline & $\begin{array}{c}\text { Non-adherent } \\
\text { B-Blocker } \\
(n=600), \%(n) \\
\end{array}$ & $\begin{array}{c}\text { Non-adherent Dual } \\
\text { Antiplatelet Therapy } \\
(\mathrm{n}=611), \% \text { (n) }\end{array}$ & $\begin{array}{c}\text { Renal } \\
\text { Dysfunction } \\
(\mathrm{n}=195), \% \text { (n) } \\
\end{array}$ \\
\hline New medication start & $1(6)$ & 0 & 0 \\
\hline Medication discontinuation & 0 & $0.2(1)$ & $17.4(34)$ \\
\hline Medication reconciliation & $4(24)$ & $0.2(2)$ & 0 \\
\hline Medication therapy adjustment & $0.5(3)$ & $0.2(1)$ & $73.8(144)$ \\
\hline Restart/resume medication & $4.2(25)$ & $6.4(39)$ & 0 \\
\hline Patient education & $46(276)$ & $73.3(448)$ & $3.6(7)$ \\
\hline Verification & $38(228)$ & $16.2(99)$ & $0.5(1)$ \\
\hline Other & $6.3(38)$ & $3.4(21)$ & $4.6(9)$ \\
\hline
\end{tabular}

conducting PHM activities on a regular cycle, this program likely provided a higher level of safety and quality care for patients. This process of proactively completing PHM activities did not exist prior to creating it for APPE students and would likely not continue to exist without them. This approach and process describes a unique way to truly maximize highly capable fourth-year PharmD students in providing added value for patients and the organization. Finally by increasing their patient care responsibilities, this approach allows students to exert a greater level of independence.

The use of an ambulatory care experiential training model focusing largely on independent PHM activities has not been previously studied or documented in the literature. In many studies, students' clinical interventions are labeled as "medication reviews" or "chart reviews" with no description of whether there was an actual action or intervention completed by the student. ${ }^{2-6}$ Although there is educational value in students assessing the appropriateness of patient medication therapy via chart reviews, if no action is taken and no interventions occur, the value of the students' work to patients and the organization is difficult to determine. In this pilot study, interventions were separated into non-actionable (chart review only) and actionable for evaluation. Of the actionable interventions conducted by students, patient education was the most common type. Almost exclusively, patient education interventions were conducted to address
nonadherence.Patient counseling regarding adherence is an actionable intervention and can be associated with a cost-avoidance value. Improving patients' understanding of medication therapy and thus improving their adherence is extremely important not only for individual patient outcomes but also for organizational safety and quality measures. Prescription verification, the second most common intervention performed by our students, provided an additional level of vigilance and improved recorded adherence rates. Patient education and verification (as they relate to adherence) correlate to quality measures for Healthcare Effectiveness Data and Information Set (HEDIS) and Five-Star Quality Rating System for Centers for Medicare \& Medicaid Services, and therefore can indirectly impact organizational goals and targets. Globally, students focusing on adherence issues may have an economic impact as medication non-adherence alone results in $\$ 100$ billion each year in hospitalizations. ${ }^{11}$

This study has some limitations. Students were responsible for documenting their interventions, thereby creating the opportunity for potential bias due to interstudent variability, which may have led to incorrect categorization or incomplete documentation. However, as previously mentioned, all students completed a standardized training process on how to properly document and record interventions within Excel. The data used to estimate the offset of clinical pharmacist time (ie, the time it took students to complete activities and for clinical

Table 3. Estimated Average Minutes of Pharmacist Time Offset Per Actionable Population Health Management (PHM) Activity

\begin{tabular}{lccc}
\hline & $\begin{array}{c}\beta \text {-Blocker } \\
\text { Non-adherence, } \\
\text { Mean (SD) }\end{array}$ & $\begin{array}{c}\text { Dual Antiplatelet Therapy } \\
\text { Non-adherence, } \\
\text { Mean (SD) }\end{array}$ & $\begin{array}{c}\text { Renal } \\
\text { Dysfunction, } \\
\text { Mean (SD) }\end{array}$ \\
\hline Student time, min & $24.2(13.2)$ & $24.7(15.0)$ & $21.7(9.7)$ \\
Pharmacist oversight time, min & $10.5(6.2)$ & $7.7(4.1)$ & $8.3(4.9)$ \\
Estimated time offset, ${ }^{a}$ min & $13.1(11.9)$ & $16.8(15.1)$ & $11.7(8.9)$ \\
\hline
\end{tabular}

${ }^{a}$ Estimated time offset $(\min )=$ average student time $(\min )$ - average pharmacist oversight time $(\min )$ 


\section{American Journal of Pharmaceutical Education 2019; 83 (5) Article 6759.}

Table 4. Total Hours of Pharmacist Time Offset Per Actionable Population Health Management (PHM) Activity Based on Estimated Average Minutes of Pharmacist Time OffSet and Number of Interventions per PHM Activity

\begin{tabular}{|c|c|c|c|c|c|c|c|}
\hline & \multirow{2}{*}{\multicolumn{2}{|c|}{\begin{tabular}{|c|} 
B Blocker \\
Non-adherence
\end{tabular}}} & \multirow{2}{*}{\multicolumn{2}{|c|}{$\begin{array}{c}\text { Dual Antiplatelet Therapy } \\
\text { Non-adherence }\end{array}$}} & \multirow{2}{*}{\multicolumn{2}{|c|}{$\begin{array}{c}\text { Renal } \\
\text { Dysfunction }\end{array}$}} & \multirow[b]{3}{*}{$\frac{\text { Total }}{(\mathrm{N}=3,774)}$} \\
\hline & & & & & & & \\
\hline & $\begin{array}{c}\text { Action } \\
(n=600)\end{array}$ & $\begin{array}{c}\text { No Action } \\
(n=940)\end{array}$ & $\begin{array}{c}\text { Action } \\
(\mathrm{n}=611)\end{array}$ & $\begin{array}{l}\text { No Action } \\
(\mathrm{n}=908)\end{array}$ & $\begin{array}{c}\text { Action } \\
(\mathrm{n}=195)\end{array}$ & $\begin{array}{c}\text { No Action } \\
(\mathrm{n}=520)\end{array}$ & \\
\hline $\begin{array}{l}\text { Time offset per intervention in } \\
\text { minutes, mean (SD) }\end{array}$ & $13.1(11.9)$ & $11(8)$ & $16.8(15.1)$ & $11(9.3)$ & $11.7(8.9)$ & $10(6.9)$ & \\
\hline Total time off-set in hours ${ }^{\mathrm{a}}$ & 131 & 172.3 & 171.1 & 166.5 & 38 & 86.7 & 765.6 \\
\hline
\end{tabular}

a (Time Offset Per Intervention (min)) x (Number of Interventions))/60 = Total Estimated Time Off-Set (hr)

pharmacists to review students) were self-reported estimates. While the purpose of this study was not to evaluate students' clinical comprehension or satisfaction with the learning experience, many students anecdotally expressed contentment with this independent learning opportunity. Also, some clinical pharmacists were able to assess APPE students informally through their involvement with the PHM activities, including students' clinical judgment, written and verbal communication skills, and time management skills. Although patients' clinical outcomes were not assessed after the student interventions, new PHM activity lists were generated for each rotation cycle. Because a patient within these list parameters would show up again on future students' lists, their status would be readdressed at that time. Although these considerations were outside the scope of this study, they may be important for future research to advance understanding of the value of PHM activity-based APPEs.

\section{CONCLUSION}

This study demonstrated that a clinically based population management approach can be used successfully within an APPE and can provide value by improving quality and safety outcomes for patients and organizations. Depending on the type of PHM activity, students would have the opportunity to complete various types of interventions. This approach can also incur clinical pharmacist time offset for the precepting organization while offering meaningful clinical interventions for patients and significant learning opportunities for students.

In summary, organizations and busy preceptors should continue to explore structured processes of training and utilization of pharmacy students to optimize the time and effort it takes pharmacists to train students and the hard work students put forth during APPEs. Other sites are encouraged to evaluate departmental or organizational goals and integrate students into these processes for the mutual benefit of preceptor, student, and patients.

\section{ACKNOWLEDGMENTS}

This study was funded by the Kaiser Permanente Colorado Pharmacy Department.

\section{REFERENCES}

1. Accreditation Council for Pharmacy Education Accreditation Standards and Key Elements for the Professional Program in Pharmacy Leading to the Doctor of Pharmacy Degree. https:// www.acpe-accredit.org/pdf/Standards2016FINAL.pdf. Accessed June 14, 2019.

2. Skrabal MZ, Jones RM, Nemire RE, et al. National survey of volunteer pharmacy preceptors. Am J Pharm Educ. 2008;72(5):Article 112.

3. Danielson J, Craddick K, Eccles D, Kwasnik A, O’Sullivan TA. Qualitative analysis of common concerns about challenges facing pharmacy experiential education programs. Am J Pharm Educ. 2015;79(1):Article 6.

4. Mersfelder TL, Bouthillier MJ. Value of the student pharmacist to experiential practice sites: a review of the literature. Ann Pharmacother. 2012;46(4):541-548.

5. Ginzurg R. Impact of pharmacy student interventions in an urban family medicine clinic. Am J Pharm Educ. 2014;78(5):Article 90.

6. Shogbon AO, Lundquist LM. Student pharmacists' clinical interventions in advanced pharmacy practice experiences at a community nonteaching hospital. Am J Pharm Educ.

2014;78(3):Article 50.

7. Woolley AB, Berds CA IV, Edwards RA, Copeland D, DiVall MV. Potential cost avoidance of pharmacy students' patient care activities during advanced pharmacy practice experiences. $A m J$ Pharm Educ. 2013;77(8):Article 164.

8. Shepler BM. Cost savings associated with pharmacy student interventions during APPEs. Am J Pharm Educ. 2014;78(4):

Article 71

9. Dalal K, McCall KL, Fike DS, Horton N, Allen A. Pharmacy students provide care comparable to pharmacists in an outpatient anticoagulation setting. Am J Pharm Educ. 2010;74(8):Article 139. 10. Sandhoff BG, Nies LK, Olson KL, Nash JD, Rasmussen JR, Merenich JA. Clinical pharmacy cardiac risk service for managing patients with coronary artery disease in a health maintenance organization. Am J Health Syst Pharm. 2007;64(1):77-84.

11. American Pharmacists Association, Pharmacists Provide Care. http://www.pharmacistsprovidecare.com/. Accessed November 6, 2016. 